\title{
Trends for Reported Discrimination in Health Care in a National Sample of Older Adults with Chronic Conditions
}

\author{
Thu T. Nguyen, $S C D^{7}$, Anusha M. Vable, $S C D^{2}$, M. Maria Glymour, $S c D^{7,3}$, and Amani Nuru-Jeter, $P h D^{4}$ \\ 'Department of Epidemiology \& Biostatistics, University of California, San Francisco, San Francisco, CA, USA; ${ }^{2}$ Center for Primary Care and \\ Outcome Research and Center for Population Health Sciences, Departments of Medicine and of Health Research and Policy, Stanford University, \\ Stanford, CA, USA; ${ }^{3}$ Department of Social and Behavioral Sciences, Harvard T.H. Chan School of Public Health, Boston, MA, USA; 'Divisions of \\ Community Health Sciences and Epidemiology, University of California, Berkeley, Berkeley, CA, USA.
}

BACKGROUND: Discrimination in health care settings is associated with poor health outcomes and may be especially harmful to individuals with chronic conditions, who need ongoing clinical care. Although efforts to reduce discrimination are growing, little is known about national trends in discrimination in health care settings.

METHODS: For Black, White, and Hispanic respondents with chronic disease in the 2008-2014 Health and Retirement Study ( $N=13,897$ individuals and 21,078 reports), we evaluated trends in patient-reported discrimination, defined based on frequency of receiving poorer service or treatment than other people from doctors or hospitals ("never" vs. all other). Respondents also reported the perceived reason for the discrimination. In addition, we evaluated whether wealth predicted lower prevalence of discrimination for Blacks or Whites. We used generalized estimating equation models to account for dependency of repeated measures on individuals and wave-specific weights to represent the US non-institutionalized population aged 54+ .

RESULTS: The estimated prevalence of experiencing discrimination in health care among Blacks with a major chronic condition was 27\% (95\% CI: 23, 30) in 2008 and declined to $20 \%(95 \% \mathrm{CI}: 17,22)$ in 2014 . Reports of receiving poorer service or treatment were stable for Whites (17\%, 95\% CI: 16, 19 in 2014). The Black-White difference in reporting any health care discrimination declined from $8.2 \%$ (95\% CI: $4.5,12.0)$ in 2008 to $2.5 \%$ (95\% CI: $-1.1,6.0$ ) in 2014. There was no clear trend for Hispanics. Blacks reported race and Whites reported age as the most common reason for discrimination.

CONCLUSIONS: Findings suggest national declines in patient-reported discrimination in health care among Blacks with chronic conditions from 2008 to 2014, although reports of discrimination remain common for all racial/ethnic groups. Our results highlight the critical importance of monitoring trends in reports of discrimination in health care to advance equity in health care.

KEY WORDS: health care; discrimination; disparities; epidemiology.

Electronic supplementary material The online version of this article (https://doi.org/10.1007/s11606-017-4209-5) contains supplementary material, which is available to authorized users.

Received May 22, 2017

Revised September 22, 2017

Accepted October 4, 2017

Published online December 15, 2017
J Gen Intern Med 33(3):291-7

DOI: $10.1007 / \mathrm{s} 11606-017-4209-5$

(c) Society of General Internal Medicine 2017

\section{INTRODUCTION}

Multiple forms of discrimination, or unfair treatment, have been linked to health. Encounters with discrimination, defined as differential treatment stemming from negative attitudes, beliefs, and judgments about members of a socially defined group $^{1-3}$ are an established correlate of negative mental and physical health outcomes, ${ }^{1,4}$ including a variety of chronic conditions such as heart disease, stroke, diabetes, and cancer. ${ }^{7}$, ${ }^{8}$ Discrimination may be especially impactful in health care settings. For patients with major chronic conditions, discriminatory experiences may reduce engagement with the medical care system. Therefore, an understanding of the proportion of patients reporting experiences of discrimination in health care and the routine monitoring of trends is important for providing informed health care.

It is well accepted that the interaction and ongoing relationship between patients and providers can support or hinder health promotion and chronic disease management. Provider bias and other elements of the doctor-patient relationship have been associated with patient satisfaction, utilization of health care services, and patient outcomes. ${ }^{9-11}$ A 2003 Institute of Medicine (IOM) report reviewed hundreds of studies and concluded that provider bias, prejudice, and stereotyping of patients may contribute to racial and ethnic disparities in health care. $^{12}$

Studies indicate that these perceptions and beliefs may, in turn, affect physicians' behaviors and health care decisionmaking. ${ }^{13,14}$ For example, internal medicine and emergency department residents were presented with a vignette of a patient with chest pain, where the patient's race was randomly assigned as Black or White. The residents also completed the Implicit Association Test (IAT) to measure implicit race preference and perceptions of cooperativeness. As implicit antiBlack bias increased, recommendations for thrombolysis for Black patients decreased. ${ }^{15}$

Recent large-scale initiatives to bring greater attention to health and health care disparities and discrimination within 
health care settings, including the Healthy People 2010 promotion, ${ }^{16}$ may have helped to reduce the frequency of discrimination in health care settings. In response to the 2003 IOM report documenting health care disparities, medical schools have developed new curricula with the goal of eliminating physician contribution to inequality in health care. ${ }^{17}$ Starting in 2015, the Medical College Admissions Test (MCAT) included new sections focused on social determinants of health. ${ }^{18}$ Efforts are also being made to revise medical curricula to incorporate training in cultural humility ${ }^{19}$ and structural competency. ${ }^{20}$ However, little is known about the effectiveness of changes in medical school training or other national efforts in reducing discrimination in the health care setting.

Although discrimination in health care has been established as common and detrimental for patient health, there is no national surveillance system to describe the frequency or trends in the prevalence of health care discrimination among patients with chronic diseases in the United States. Chronic disease management requires ongoing encounters with various facets of the health care system. Further, those with chronic diseases are particularly vulnerable given their increased need for timely ongoing care, where both differential treatment and decreased patient engagement due to provider mistrust may lead to adverse health events. This paper provides national estimates of changes over time in patient-reported discrimination in health care in representative samples of older Americans with chronic disease. A critical aspect of measuring health care quality is patient-reported experiences. ${ }^{21}$ Examining trends and the current state of patient-reported discrimination in health care will aid in quantifying the pervasiveness of these experiences among US populations and in setting targets for intervention.

Prior evidence suggests that reports of discrimination vary by race, and that race and socioeconomic status (SES) may interact in shaping reports of discrimination. For example, Blacks are more likely than Whites to report racial discrimination. ${ }^{22-24}$ Further, Blacks reporting racial discrimination are more likely to report higher levels of educational attainment and income than those reporting no discrimination. ${ }^{25}$ Among Whites, the inverse pattern holds: Whites with less education and income are more likely to report racial discrimination. ${ }^{25}$ These findings suggest the need for race-specific data on discrimination and testing for interactions between race and SES. To address these gaps, we present race-specific trends in the reporting of health care discrimination. We also test for interactions between race/ethnicity and wealth in examining predictors of reports of health care discrimination.

Understanding the attributed reason for the discrimination may also provide more specificity and inform efforts to reduce discrimination within the health care system. In this paper, we use nationally representative data on US adults aged 54+ with major chronic conditions to evaluate trends in reports of discrimination in health care, including attribution of discrimination by race/ethnicity.

\section{METHODS}

\section{Sample}

We use data from the Health and Retirement Study (HRS), a nationally representative study of US adults aged 54+, to examine patient-reported discrimination in health care over time among those reporting a history of chronic disease. Participants were identified as having a chronic condition if they reported that their doctor had ever informed them that they had hypertension, diabetes, cancer, lung disease, heart condition, or stroke. HRS was initiated in 1992, but to maintain representativeness, new cohorts of individuals who have aged into HRS eligibility are added every 6 years; such a cohort was enrolled in 2010. The current analyses use data from 2008 to 2014 (years when questions on discrimination in health care were included in the survey). Questions on discrimination were fielded in each biennial wave to a rotating, random sample of $50 \%$ of HRS participants who completed the in-person interview during that wave. Data were collected from the other half of the core participants in alternate waves. Thus, every 4 years, we have repeated measurements on patient-reported discrimination for the same half sample ( $N=13,897$ individuals with information on health care discrimination, for a total of 21,078 reports). This study was approved by the University of California, San Francisco, Institutional Review Board.

Health Care Discrimination. In HRS, discrimination is assessed using the Everyday Discrimination Scale (short version) to determine chronicity of discrimination in six different social situations. ${ }^{26}$ For this analysis, we examined responses to the item regarding how frequently, in their day-today lives, respondents received poorer service or treatment than other people from doctors or hospitals. Response options included "almost every day," "at least once a week," "a few times a month," "a few times a year," "less than once a year," and "never." Discrimination in health care was coded as a dichotomous variable as those reporting any frequency of discrimination in health care compared to those reporting "never." As an alternative categorization, we also compared the prevalence of reporting discrimination "a few times a year" or more (coded as 1) to those reporting discrimination "less than once a year" or "never" (coded as 0 ) to examine trends in higher frequency of reported health care discrimination.

Participants who reported any frequency of discrimination were asked a follow-up question about the potential reasons for the discrimination. Response options were collapsed and categorized as (1) race/ancestry/national origin, (2) gender, (3) age, (4) religion, (5) weight/physical appearance, (6) physical disability, (7) sexual orientation, (8) financial status, or (9) other, with participants marking all that applied. Attribution patterns were very similar throughout the period 2008-2014. For simplicity, we present attribution results for 2008 in the main text and 2010-2014 results in the online supplementary materials. 
Covariates. We examined the following sociodemographic variables as predictors of health care discrimination: age, gender, race/ethnicity (non-Hispanic Black, and Hispanic vs. non-Hispanic White [reference]; note that non-Hispanic Whites and non-Hispanic Blacks are hereafter referred to as "Whites" and "Blacks," respectively), educational attainment (continuous years of schooling), log-household size-adjusted wealth (with negative wealth recoded as 0 and log values centered at 10.13 , or approximately $\$ 25,000$ ), current employment status (yes/no), marital status (married/partnered vs. not married/partnered), and indicators for year of interview. Approximately $90 \%$ of the analytic sample had health insurance. Health insurance status was excluded based on a priori decisions. However, it was included as a covariate in sensitivity analyses (eTable 1 in the supplement). The results remained very similar and conclusions did not change with adjustment for insurance status. As time-varying covariates, marital status, employment status, and wealth were updated with each wave of data; however, because data on these covariates were not yet available for 2014, we carried forward the previous wave's (2012) covariate data.

Statistical Analyses. We estimated the national prevalence of patient-reported discrimination in health care in 2008, 2010, 2012, and 2014, applying the HRS wave-specific sampling weights to represent the US non-institutionalized population aged 54+. We tested for race/ethnicity-specific linear trends in reports of discrimination in health care by fitting generalized estimating equation (GEE) models with a continuous linear term for year, specifying an exchangeable working correlation structure to take account of the fact that some individuals contributed to two waves of data.
To examine associations between sociodemographic characteristics and reports of health care discrimination, we built three nested GEE models, adjusting for additional covariates in each model. In model 1, we adjusted for age, gender, race/ethnicity, and indicators for year of interview. In model 2 , we additionally adjusted for years of schooling and timevarying confounders: log-household size-adjusted wealth, current employment (yes/no), and marital status (married/ partnered yes/no). In model 3, we tested for the presence of interaction between race/ethnicity and wealth. As sensitivity analyses, we examined interactions between race/ethnicity and education (eTable 2 in the supplement).

\section{RESULTS}

The mean age of respondents across waves was 69 years (Table 1). Almost half were male (45-46\%), and the majority were White (79-82\%). Reports of discrimination in health care were common among Blacks in all years, but showed an overall decline between 2008 and 2014 (Fig. 1). The largest decrease in reports of any health care discrimination among Blacks occurred in the beginning of this period, with $27 \%$ reporting receiving poorer service or treatment from doctors or hospitals in 2008 , declining to $21 \%$ in 2010 , and more modestly to $20 \%$ in 2014 . Among White participants, reports of receiving poorer service or treatment remained nearly constant at $18 \%$ in 2008 and $17 \%$ in 2014 (Fig. 1). The Black-White difference in report of any health care discrimination declined from $8.2 \%$ (95\% CI: $4.5,12.0$ ) in 2008 to $2.5 \%$ (95\% CI: -1.1 , $6.0)$ in 2014. Tests for a linear trend of reports of any discrimination in health care were statistically significant for Blacks

Table 1 Demographic Characteristics of Analytic Sample, Raw Unweighted Numbers and Weighted Percentages*

\begin{tabular}{|c|c|c|c|c|}
\hline \multirow[t]{2}{*}{ Characteristic } & \multirow{2}{*}{$\begin{array}{l}2008(N=5105) \\
\text { No. }(\%)\end{array}$} & \multirow{2}{*}{$\begin{array}{l}2010(N=5405) \\
\text { No. }(\%)\end{array}$} & \multirow{2}{*}{$\begin{array}{l}2012(N=5146) \\
\text { No. }(\%)\end{array}$} & \multirow{2}{*}{$\begin{array}{l}2014(N=5422) \\
\text { No. }(\%)\end{array}$} \\
\hline & & & & \\
\hline Age (mean, SD) & $68.7(9.8)$ & $68.7(9.8)$ & $68.4(9.7)$ & $69.2(9.6)$ \\
\hline Male & $2163(44.7)$ & $2347(46.4)$ & $2204(45.8)$ & $2269(46.2)$ \\
\hline \multicolumn{5}{|l|}{ Race/ethnicity } \\
\hline White & $3873(81.2)$ & $3968(82.3)$ & 3587 (80.9) & $3696(79.4)$ \\
\hline Black & $709(9.4)$ & $853(9.0)$ & $880(9.4)$ & $985(9.8)$ \\
\hline Hispanic & $414(6.8)$ & $458(6.2)$ & $541(6.8)$ & $590(7.7)$ \\
\hline Other & $108(2.6)$ & $124(2.6)$ & $132(2.9)$ & $146(3.1)$ \\
\hline US-born & $4658(91.9)$ & $4926(92.50)$ & $4612(92.1)$ & $4829(91.1)$ \\
\hline Years of schooling (mean, SD) & $12.7(3.7)$ & $13.1(4.3)$ & $13.4(6.2)$ & $13.4(5.1)$ \\
\hline Married/partnered & $3157(63.2)$ & $3451(65.4)$ & $3184(63.5)$ & $3401(65.8)$ \\
\hline Currently employed & $1398(34.4)$ & $1514(33.4)$ & $1429(33.9)$ & $1755(39.8)$ \\
\hline Wealth (median, interquartile range) & $138,593(373,616)$ & $144,316(356,389)$ & $127,988(347,172)$ & $120,915(342,777)$ \\
\hline \multicolumn{5}{|l|}{ Chronic conditions } \\
\hline High blood pressure & $3940(77.2)$ & $4258(78.8)$ & 4008 (77.9) & $4344(80.8)$ \\
\hline Diabetes & $1332(26.1)$ & $1564(29.0)$ & $1487(28.9)$ & $1603(29.9)$ \\
\hline Cancer & $1026(20.1)$ & $1101(20.4)$ & $1110(21.6)$ & $1141(21.1)$ \\
\hline Lung disease & $704(13.8)$ & $724(13.4)$ & $723(14.1)$ & $705(13.1)$ \\
\hline Heart condition & $1679(32.9)$ & $1716(31.8)$ & $1728(33.7)$ & $1697(31.6)$ \\
\hline Stroke & $561(11.0)$ & $511(9.5)$ & $520(10.1)$ & $425(7.9)$ \\
\hline
\end{tabular}

*Numbers are unweighted; percentages are weighted, applying year-specific weights to represent the US non-institutionalized population aged 54+ with at least one chronic condition 


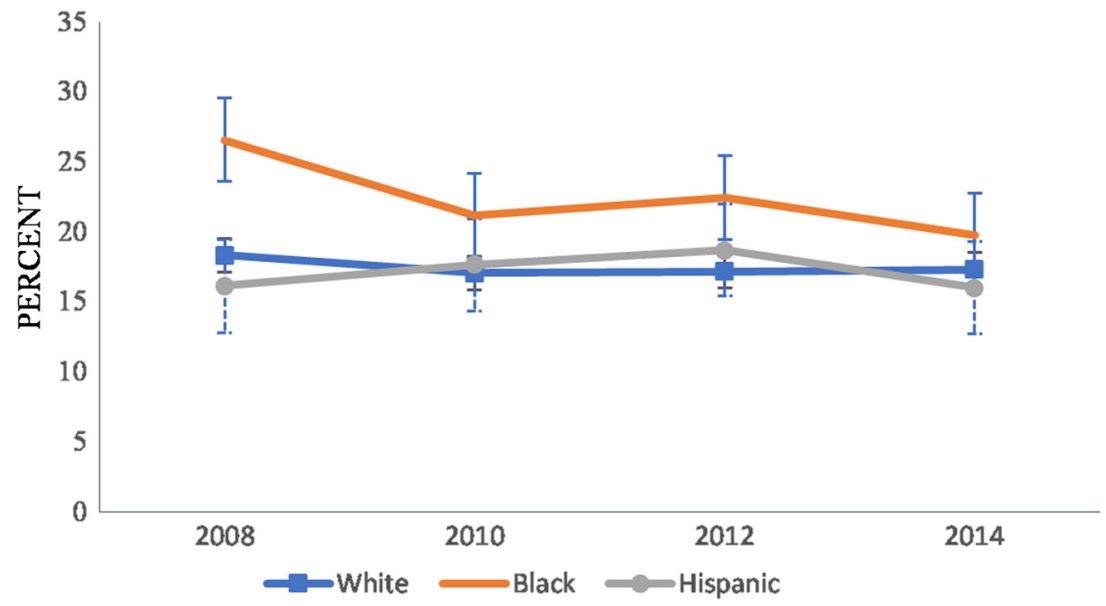

Figure 1 Trends in percentage of respondents reporting any health care discrimination by race/ethnicity.

$(p=0.01)$ but not for Whites $(p=0.24)$ or Hispanics $(p=0.91)$

(Table 2).

In 2008, attribution of discrimination varied markedly by race and ethnicity. Among Whites, age (29\%), weight or other physical appearance characteristic $(16 \%)$, gender $(10 \%)$, and financial status $(10 \%)$ were the most frequently reported reasons for discrimination in 2008 and were fairly constant across years (Fig. 2). Among Blacks, race or ancestry (48\%), age (29\%), and financial status $(20 \%)$ were the most frequently reported in 2008. The top reported reasons for discrimination for Hispanics were age (27\%), race or ancestry (23\%), weight/ physical appearance (14\%), and financial status (14\%; Fig. 2). These attribution patterns were similar for the 2010-2014 period (eFigures 1-3 in the supplement).

In model 1, adjusting for age, gender, and year indicators, Blacks were more likely than Whites to report any discrimination in health care (OR: 1.29, 95\% CI: 1.14, 1.48). In the fully adjusted model (model 2), men were more likely than women to report any heath care discrimination (OR: 1.18, 95\% CI: 1.06, 1.30), while age (OR: 0.97, 95\% CI: 0.97, 0.98), log-household size-adjusted wealth (OR:0.97, 95\% CI: 0.96, 0.98), current employment (OR: 0.87, 95\% CI: 0.78, 0.98), and being married

Table 2 Race/Ethnicity-Specific Yearly Trends in Patient-Reported Receipt of Poorer Service or Treatment from Doctors or Hospitals, Annualized Change, 2008-2014*

\begin{tabular}{lrc}
\hline \hline & OR (95\% CI) & $p$-value \\
\hline Annual trend in "any frequency" ${ }^{\circ}$ & \\
Black & $0.95(0.91,0.99)$ & 0.01 \\
White & $0.99(0.97,1.01)$ & 0.24 \\
Hispanic & $1.00(0.94,1.06)$ & 0.91 \\
Annual trend in "a few times a year or more" & \\
Black & $0.94(0.88,1.00)$ & 0.04 \\
White & $1.00(0.96,1.04)$ & 0.99 \\
Hispanic & $1.00(0.93,1.07)$ & 0.98 \\
\hline
\end{tabular}

*Generalized estimating equation model, logit link with continuous term for year. Estimates are based on applying year-specific weights to represent the US non-institutionalized population aged 54+ with at least one chronic condition

tAny frequency includes respondents who endorsed any response other than "never"
(OR: 0.84, 95\% CI: 0.76, 0.94) were all associated with lower odds of reporting any health care discrimination (Table 3 ). Socioeconomic status variables including education, wealth, and employment status, which correlate with race/ethnicity, were added in model 2; this may explain why the Black-White estimate became non-significant in model 2. However, the estimated effect of being Black becomes significant again once we allow for interactions between race/ethnicity and wealth (model 3). Results were largely similar when examining reports of receiving poorer service or treatment a few times a year or more (eTable 4 in the supplement).

The statistically significant Black* $\ln$ (wealth) interaction indicates that the association between wealth and discrimination differed between Blacks and Whites (model 3; Table 3). Figure 3 presents the predicted probabilities of reporting any discrimination in health care using estimates from model 3 , and indicates that although the predicted probability tended to decline with increasing wealth for Whites, it remained nearly the same regardless of wealth for Blacks. These results suggest that although higher wealth was associated with fewer reports of discrimination among Whites, it had no benefit for Blacks. A similar Black-by-wealth interaction was found for reports of discrimination at least a few times a year (eTable 4 in the supplement).

\section{DISCUSSION}

Patient reports of discrimination in health care were common in all racial/ethnic groups in this nationally representative sample of older adults with chronic disease. Findings suggest a declining prevalence of reports of discrimination in health care from 2008 to 2014 for Blacks, though reports of discrimination in the health care setting remain frequent for Blacks and all other racial/ethnic groups.

This paper examines patient-reported discrimination in health care. We did not examine objective indicators of receipt of care. Patient-reported discrimination in the health care 


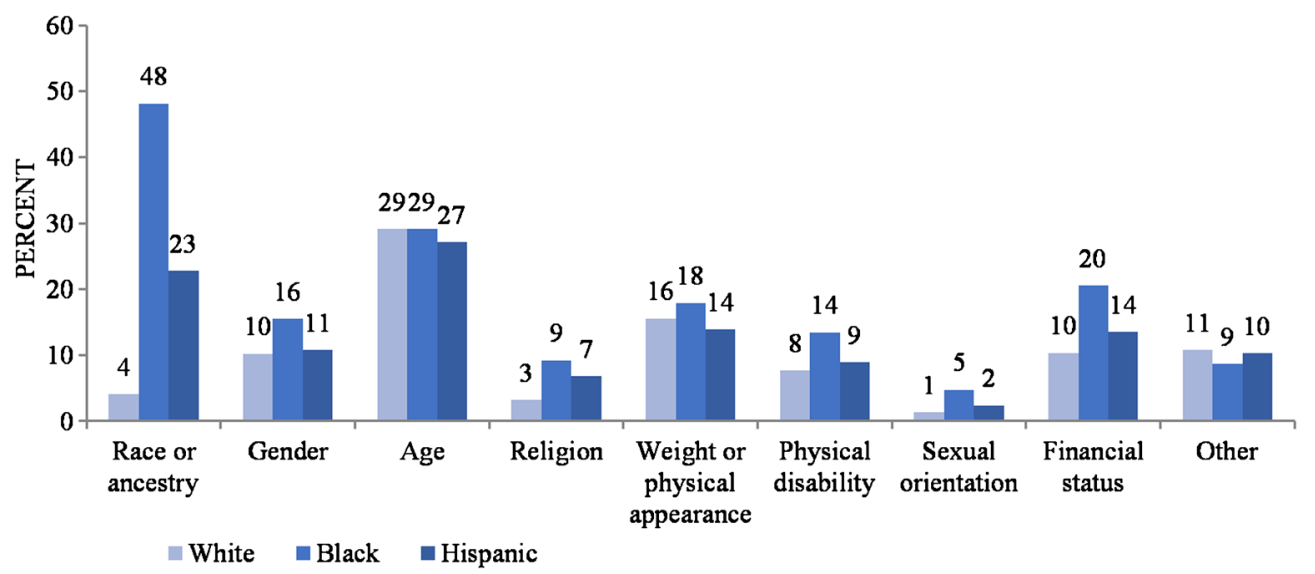

Figure 2 Weighted attribution of discrimination in 2008 among those with chronic conditions who reported any discrimination. Respondents could endorse multiple attributions.

setting has been associated with worse health, ${ }^{27}$ lower satisfaction with health care, ${ }^{28}$ and lower utilization of health services. $^{29}$ Patient-reported discrimination is of intrinsic importance, since internal appraisal is associated with behavioral responses and is a critical component in predicting biological stress responses. ${ }^{30-33}$ Provider-patient encounters are likely to be affected by patients' past experiences with discrimination, regardless of objective indicators of care processes. One limitation of self-reports of discrimination, however, is that individuals may appraise an event as threatening but use coping strategies (e.g., denial, ignoring it, reinterpretation of events) that limit their ability or inclination to report the event. ${ }^{34,35}$

Additionally, discrimination in health care was assessed using one item from a six-item scale assessing everyday experiences of discrimination. Future research intended to replicate or expand upon these findings should consider using validated scales measuring health care discrimination ${ }^{36}$ to better assess reported discrimination in this setting. The current paper employed an individual-level analysis. Multi-level studies evaluating regional or hospital-level variation in reported discrimination may be valuable as well. New cohorts were also added every 6 years, with a new cohort added in 2010. Although we used restrictions in each case to maintain the same age range and applied weighting to achieve a nationally representative sample for people of that age group, it is nonetheless possible that some observed fluctuations in the reports of discrimination were due to the addition of a new cohort. This may be one explanation for the larger drop in reports of discrimination among Blacks from 2008 to 2010 and slower declines in 2010-2014, although we saw no such change for Whites or Hispanics. The restriction to participants who were informed by their doctor that they had hypertension, diabetes, cancer, lung disease, heart conditions, or stroke may have excluded participants who had these chronic conditions but were unaware of their status due to low health care utilization. The current analyses also did not account for selective mortality, because we wished to describe trends only among living patients.

To our knowledge, there is no previous literature on national trends in reports of discrimination in health care among adult patients with chronic conditions, who may have more

Table 3 Association between Sociodemographic Characteristics and Reporting Any Health Care Discrimination*

\begin{tabular}{|c|c|c|c|}
\hline & Model 1 & Model 2 & Model 3 \\
\hline & OR $(95 \%$ CI $)$ & OR (95\% CI) & OR $(95 \% \mathrm{CI})$ \\
\hline Black & $1.29(1.14,1.48)$ & $1.11(0.96,1.28)$ & $1.21(1.05,1.40)$ \\
\hline Hispanic & $0.90(0.75,1.09)$ & $0.80(0.66,0.98)$ & $0.82(0.67,1.00)$ \\
\hline Year 2010 & $0.89(0.79,1.00)$ & $0.88(0.78,0.99)$ & $0.88(0.78,0.99)$ \\
\hline Year 2012 & $0.91(0.82,1.02)$ & $0.90(0.80,1.00)$ & $0.89(0.80,1.00)$ \\
\hline Year 2014 & $0.92(0.81,1.04)$ & $0.91(0.80,1.03)$ & $0.91(0.80,1.03)$ \\
\hline Age & $0.97(0.97,0.98)$ & $0.97(0.97,0.98)$ & $0.97(0.97,0.98)$ \\
\hline Male & $1.11(1.01,1.23)$ & $1.18(1.06,1.30)$ & $1.18(1.06,1.30)$ \\
\hline Education $^{\dagger}$ & & $1.00(0.99,1.01)$ & $1.00(0.99,1.01)$ \\
\hline Lnwealth $^{+}$ & & $0.97(0.96,0.98)$ & $0.96(0.94,0.97)$ \\
\hline Work & & $0.87(0.78,0.98)$ & $0.87(0.78,0.97)$ \\
\hline Married & & $0.84(0.76,0.94)$ & $0.84(0.76,0.94)$ \\
\hline Black*Lnwealth & & & $1.05(1.02,1.08)$ \\
\hline Hispanic*Lnwealth & & & $1.02(0.98,1.07)$ \\
\hline
\end{tabular}

*Estimates are based on applying year-specific weights to represent the US non-institutionalized population aged 54+ with at least one chronic condition

† Years of education centered at 12 years

$\ddagger$ Lnwealth (Logged wealth) centered at 10.1269, $\$ 25,000$ 


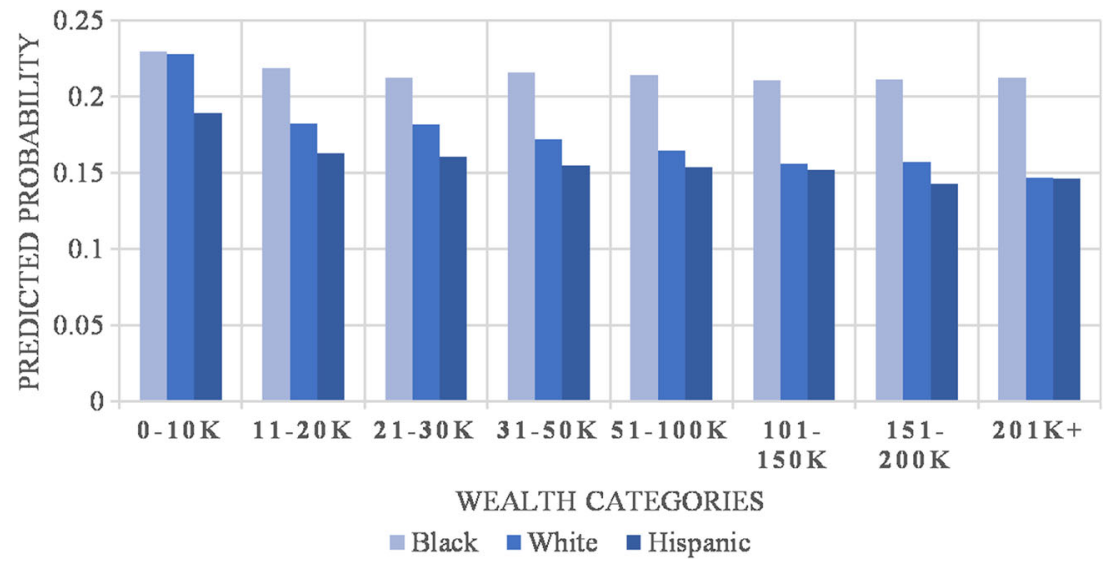

Figure 3 Predicted probability of reporting any discrimination in health care by wealth category and race/ethnicity.

continuous interactions with the health care system. Previous studies have tended to examine discrimination in localized settings using select patient samples. ${ }^{23,}{ }^{37-39}$ A prior study utilizing data from HRS examined discrimination in the health care setting in 2008 only. ${ }^{40}$ Our finding that reports of discrimination are common, especially for Blacks, is consistent with prior literature. ${ }^{22-24}$ These results, along with previous findings, highlight the pervasiveness of patient-reported discrimination in the health care setting. Patients with chronic conditions rather than acute medical issues require more routine follow-up care, potentially exacerbating health effects associated with patientprovider interactions, where providers may refer to the health care provider or interactions that occur within the health care setting more generally. The focus on patients with major chronic conditions - conditions for which there are effective and appropriate medical management strategies - makes the prevalence of discrimination in health care particularly meaningful.

Our finding that wealth was inversely associated with reports of discrimination in health care among White patients but not Black patients is consistent with prior literature. In previous studies, higher education and income have been positively associated with reports of racial discrimination among African Americans, but for Whites the opposite is true. ${ }^{24,} 25$ Studies show that lower-SES groups are more likely to minimize attributions to discrimination, engage in selfblame, and use more passive coping strategies (e.g., denial, suppression) relative to their higher SES counterparts. ${ }^{34,41-43}$

We aimed to establish a baseline examination of discrimination in the health care setting for older US adults with chronic disease. Providers should be aware that a large fraction of patients will have experienced some form of discrimination in a health care setting, which may impact satisfaction with and utilization of care and patient-provider relationships more broadly. Given the various ways in which discrimination and bias may operate, providers and other staff within health care settings should consider how bias may impact the receipt of care. The current study indicates that reports of discrimination in the health care setting remain common. Continual monitoring of trends is important in order to track changes in reports of discrimination and to determine whether reported discrimination among Blacks continues to decline. Additionally, simply recognizing how common these experiences are for patients may help clinicians provide more appropriate, patientcentered care. Ongoing efforts are needed to eliminate discrimination and to monitor progress toward achieving equity in clinical interactions.

Corresponding Author: Thu T. Nguyen, ScD; Department of Epidemiology \& Biostatistics University of California, San Francisco, San Francisco, CA, USA (e-mail: Thu.Nguyen@ucsf.edu).

Funding/Support Dr. Nguyen's work was supported by the American Heart Association Western States Affiliate Postdoctoral Fellowship, award number 16POST29660005. The funder had no role in the design and conduct of the study, the data analysis and interpretation, review and approval of the manuscript, or decision to submit the manuscript for publication.

\section{Compliance with Ethical Standards:}

Conflict of Interest: The authors declare that they do not have a conflict of interest.

\section{REFERENCES}

1. Pascoe EA, Smart Richman L. Perceived discrimination and health: a meta-analytic review. Psychol Bull. 2009;135(4):531-54.

2. Williams DR, Mohammed SA. Racism and Health I: Pathways and Scientific Evidence. Am Behav Sci. 2013;57:1152-73.

3. Bonilla-Silva E. Rethinking Racism: Toward a Structural Interpretation. Am Sociol Rev. 1997;62(3):465-80.

4. Harris R, Tobias M, Jeffreys M, Waldegrave K, Karlsen S, Nazroo J. Effects of self-reported racial discrimination and deprivation on Maori health and inequalities in New Zealand: cross-sectional study. Lancet 2006;367(9527):2005-9.

5. Kessler RC, Mickelson KD, Williams DR. The prevalence, distribution, and mental health correlates of perceived discrimination in the United States. J Health Soc Behav. 1999;40(3):208-30.

6. Ayalon L, Gum AM. The relationships between major lifetime discrimination, everyday discrimination, and mental health in three racial and ethnic groups of older adults. Aging Ment Health. 2011;15(5):58-94.

7. Sutin AR, Stephan Y, Carretta H, Terracciano A. Perceived discrimination and physical, cognitive, and emotional health in older adulthood. Am J Geriatr Psychiatry. 2015;23(2):171-9. 
8. Luo Y, Xu J, Granberg E, Wentworth WM. A longitudinal study of social status, perceived discrimination, and physical and emotional health among older adults. Research on Aging. 2012;34(3):275-301.

9. Laveist TA, Nuru-Jeter A. Is doctor-patient race concordance associated with greater satisfaction with care? J Health Soc Behav. 2002;43(3):296306.

10. Saha S, Arbelaez JJ, Cooper LA. Patient-physician relationships and racial disparities in the quality of health care. Am J Public Health. 2003;93(10): 1713-19

11. Cooper LA, Roter DL, Carson KA, et al. The associations of clinicians' implicit attitudes about race with medical visit communication and patient ratings of interpersonal care. Am J Public Health. 2012;102(5):979-87.

12. Smedley B, Stith A, Nelson A, eds. Unequal Treatment: Confronting Racial and Ethnic Disparities in Health Care. Washington, DC: National Academy Press; 2003.

13. Chapman EN, Kaatz A, Carnes M. Physicians and Implicit Bias: How Doctors May Unwittingly Perpetuate Health Care Disparities. J Gen Intern Med. 2013;28(11):1504-10.

14. Penner LA, Dovidio JF, West TV, et al. Aversive Racism and Medical Interactions with Black Patients: A Field Study. J Exp Soc Psychol. 2010;46(2):436-40.

15. Green AR, Carney DR, Pallin DJ, et al. Implicit bias among physicians and its prediction of thrombolysis decisions for Black and White patients. J Gen Intern Med. 2007;22(9):1231-8.

16. Healthy People 2010. http://www.healthypeople.gov/2010/Document/ pdf/uih/uih.pdf. Accessed 23 Jan 2017.

17. van Ryn M, Hardeman R, Phelan SM, et al. Medical School Experiences Associated with Change in Implicit Racial Bias Among 3547 Students: A Medical Student CHANGES Study Report. J Gen Intern Med. 2015;30(12): 1748-56.

18. Association of American Medical Colleges. Achieving Health Equity: How Academic Medicine Is Addressing the Social Determinants of Health. 2016; https://www.aamc.org/download/460392/data/sdoharticles.pdf. Accessed 2 Feb 2017.

19. Tervalon M, Murray-Garcia J. Cultural humility versus cultural competence: a critical distinction in defining physician training outcomes in multicultural education. J Health Care Poor Underserved. 1998;9(2):11725.

20. Reich AD, Hansen HB, Link BG. Fundamental Interventions: How Clinicians Can Address the Fundamental Causes of Disease. J Bioeth Inq. 2016;13(2):185-92.

21. Weldring T, Smith SMS. Patient-Reported Outcomes (PROs) and PatientReported Outcome Measures (PROMs). Health Serv Insights. 2013;6:618.

22. Bratter JL, Gorman BK. Is Discrimination an Equal Opportunity Risk? Racial Experiences, Socioeconomic Status, and Health Status among Black and White Adults. J Health Soc Behav. 2011;52(3):365-82.

23. Mustillo S, Krieger N, Gunderson EP, Sidney S, McCreath H, Kiefe CI. Self-reported experiences of racial discrimination and Black-White differences in preterm and low-birthweight deliveries: the CARDIA Study. Am J Public Health. 2004;94(12):2125-31.

24. Pew Research Center. Views on Race and Inequality, Blacks and Whites are Worlds Apart. http://www.pewsocialtrends.org/2016/06/27/5-personal-experiences-with-discrimination/. Accessed 16 Jan 2017.

25. Borrell LN, Jacobs DR, Jr, Williams DR, Pletcher MJ, Houston TK, Kiefe CI. Self-reported racial discrimination and substance use in the
Coronary Artery Risk Development in Adults Study. Am J Epidemiol. 2007;166(9):1068-79.

26. Sternthal M, Slopen N, Williams DR. Racial Disparities in Health: How Much Does Stress Really Matter? Du Bois Review. 2011;8:95-113.

27. Baggio S, Iglesias K, Hugli O, et al. Associations between perceived discrimination and health status among frequent Emergency Department users. Eur J Emerg Med. 2015.

28. Weech-Maldonado R, Hall A, Bryant T, Jenkins KA, Elliott MN. The Relationship Between Perceived Discrimination and Patient Experiences With Health Care. Med Care. 2012;50:S62-8.

29. Skosireva A, O'Campo P, Zerger S, Chambers C, Gapka S, Stergiopoulos V. Different faces of discrimination: perceived discrimination among homeless adults with mental illness in healthcare settings. BMC Health Serv Res. 2014;14(1):376

30. Dickerson SS, Gable SL, Irwin MR, Aziz N, Kemeny ME. Socialevaluative threat and proinflammatory cytokine regulation: an experimental laboratory investigation. Psychol Sci. 2009;20(10):1237-44.

31. Dickerson SS, Gruenewald TL, Kemeny ME. When the social self is threatened: shame, physiology, and health. J Pers. 2004;72(6):11911216.

32. Kressin NR, Raymond KL, Manze M. Perceptions of Race/EthnicityBased Discrimination: A Review of Measures and Evaluation of their Usefulness for the Health Care Setting. J Health Care Poor Underserved. 2008;19(3):697-730.

33. Utsey so. Assessing the Stressful Effects of Racism: A Review of Instrumentation. J Black Psychol. 1998:24(3):269-88.

34. Krieger N, Sidney $\mathbf{S}$. Racial discrimination and blood pressure: the CARDIA Study of young Black and White adults. Am J Public Health. 1996;86(10):1370-8.

35. Nuru-Jeter A, Dominguez TP, Hammond WP, et al. It's the skin you're in: African-American women talk about their experiences of racism. An exploratory study to develop measures of racism for birth outcome studies. Matern Child Health J. 2009;13(1):29-39.

36. Shavers VL, Fagan P, Jones D, et al. The State of Research on Racial/ Ethnic Discrimination in The Receipt of Health Care. Am J Public Health. 2012;102(5):953-66

37. Piette JD, Bibbins-Domingo $\mathbf{K}$, Schillinger $\mathbf{D}$. Health care discrimination, processes of care, and diabetes patients' health status. Patient Educ Couns. 2006;60(1):41-8.

38. Greer TM. Perceived racial discrimination in clinical encounters among African American hypertensive patients. J Health Care Poor Underserved. 2010;21(1):251-63.

39. Hausmann LR, Kressin NR, Hanusa BH, Ibrahim SA. Perceived racial discrimination in health care and its association with patients' healthcare experiences: does the measure matter? Ethn Dis. 2010;20(1):40-7.

40. Rogers S, Thrasher A, Miao Y, Boscardin WJ, Smith A. Discrimination in Healthcare Settings is Associated with Disability in Older Adults: Health and Retirement Study, 2008-2012. J Gen Intern Med. 2015:1-8.

41. Major B, Feinstein J, Crocker J. Attributional Ambiguity of Affirmative Action. Basic Appl Soc Psych. 1994;15(1-2):113-41.

42. Chae DH, Nuru-Jeter AM, Adler NE. Implicit racial bias as a moderator of the association between racial discrimination and hypertension: a study of Midlife African American men. Psychosom Med. 2012;74(9):961-4.

43. Chae DH, Nuru-Jeter AM, Adler NE, et al. Discrimination, racial bias, and telomere length in African-American men. Am J Prev Med. 2014;46(2):103-11. 